\title{
Botulinum Neurotoxins for Post-Stroke Spasticity in Adults: A Systematic Review
}

\author{
Antonio Emanuele Elia, MD ${ }^{1,2}$ Graziella Filippini, $\mathrm{MD},{ }^{1}$ Daniela Calandrella, MD, ${ }^{1,2}$ \\ and Alberto Albanese, $\mathrm{MD}^{1,2 *}$ \\ ${ }^{I}$ Fondazione IRCCS Istituto Neurologico Carlo Besta, Milano, Italy \\ ${ }^{2}$ Università Cattolica del Sacro Cuore, Milano, Italy
}

\begin{abstract}
The aim of this systematic review was to determine whether botulinum neurotoxin (BoNT) reduce spasticity or improve function in adult patients after stroke. Eleven double-blind randomized placebo-controlled trials met inclusion criteria. They encompassed 782 patients, 767 (98\%) of whom received BoNT/A, and 15 (2\%) BoNT/B. Most studies used the Ashworth scale as primary outcome measure. Differences between treated and control groups were assessed as categorical or continuous comparisons. The overall effect on upper limb spasticity was in favor of BoNT/A. A significantly higher number of patients had a reduction of upper limb spasticity at 4-week and 8-week evaluations in the treatment group compared with placebo. Mean changes in joint spasticity revealed improvement 3 to 6 weeks and 9 to 12
\end{abstract}

weeks after treatment. There were insufficient data to establish BoNT/A efficacy on lower limb spasticity or the effect of BoNT/B on the upper and lower limbs. Because of inconsistency and heterogeneity of the available data, it was not possible to perform a meta-analysis on disability and patients' reported outcomes. There was an overlapping safety profile between the treatment and the placebo groups. BoNT/ A reduces upper limb spasticity in patients post-stroke, but the improvement in functional ability remains to be established. This gap needs to be filled by new studies to assess the effect of BoNT in the context of multidisciplinary patient management. (c) 2009 Movement Disorder Society

Key words: botulinum toxin; spasticity; stroke; metaanalysis

\section{INTRODUCTION}

In adults, stroke is the most common cause of upper motor neuron syndrome, that follows damage to the direct and indirect descending corticospinal fibers. ${ }^{1}$ Spasticity develops few days or weeks after stroke and is characterized by an increase in muscle tone and a velocity-dependent increase in tonic stretch reflexes, ${ }^{2}$ that is associated to muscle weakness. The combination of hypertonia and paralysis, which characterizes the upper motor neuron syndrome, predisposes to the de-

This article is part of the journal's online CME program. The CME activity including form, can be found online at http://www. movementdisorders.org/education/journalcme/

*Correspondence to: Dr. Alberto Albanese, Fondazione Istituto Neurologico Carlo Besta, Via G. Celoria, 11, Milano 20133, Italy

E-mail: alberto.albanese@unicatt.it

Potential conflict of interest: Nothing to report.

Received 6 August 2008; Revised 28 November 2008; Accepted 3 December 2008

Published online 17 February 2009 in Wiley InterScience (www. interscience.wiley.com). DOI: $10.1002 / \mathrm{mds.22452}$ velopment of contractures leading to further impairment. It is unclear whether functional improvement following stroke occurs in parallel with the reduction of spastic hypertonia. ${ }^{3}$

Numerous treatments are used to reduce spasticity. Botulinum neurotoxin (BoNT) injections are employed as focal antispastic agents usually as part of complex rehabilitation regimens. ${ }^{4}$ Treatment plans must consider a trade-off between reduction of spastic hypertonia and preservation of residual motor function. ${ }^{5}$ Active function relates to the capacity to move the body or its parts actively and can range from simple active movements at a specified joint to complex movements and even complex actions; passive function relates to the ability to integrate a body part in activities passively. ${ }^{6}$ Functional treatment goals in patients with spasticity include improvement of active and passive function, reduction of pain associated with passive mobilization and painful spasms, improvement of hygiene and prevention of contractures. 
There is no consensus as to when BoNT treatment should be initiated, or how long it should last; furthermore, it remains unsettled if BoNT treatment improves daily living activities in post-stroke patients. There are a number of possible reasons for this uncertainty: first, it is possible that weakness, more than spasticity, contributes to disability ${ }^{3}$; second, studies may have been inadequately powered to detect functional gain; third, the outcome measures on function may have been insufficiently sensitive. ${ }^{7}$

We reviewed the available evidence on the use of BoNT in adult patients with stabilized spasticity, and evaluated its efficacy on motor and functional outcome measures.

\section{PATIENTS AND METHODS}

Double-blind randomized placebo controlled trials were included; quasi-randomized, nonrandomized, single-blinded, and nonblinded trials were excluded. Trials where the comparisons of interest were confounded by other antispastic treatments were also excluded. The trials included were on adult patients ( $>15$ years) with post-stroke spasticity assessed by the normal, ${ }^{8}$ modified, ${ }^{9}$ or expanded ${ }^{10}$ versions of the Ashworth scale. Interventions considered were intramuscular injections of type A BoNT (BoNT/A) or type B BoNT $(\mathrm{BoNT} / \mathrm{B})$ in stabilized patients, regardless of the dose, number of treatments, and time from stroke onset to treatment.

Two primary outcomes were chosen: change of Ashworth scores in each upper or lower limb joint, and number of patients with at least a two-point reduction in Ashworth scores observed at 3- to 6-week or 8- to 12-week follow-up visits after BoNT treatment. The following secondary outcome measures were also assessed: improvement of global assessment scale $(\mathrm{GAS})^{11}$; area under the curve of Ashworth scores changes from baseline to the end of follow-up; functional disability, pain, and quality of life measured by validated scales; occurrence of serious adverse events.

\section{Search Strategy}

The following were searched: MEDLINE (1966 to September 2006), EMBASE (1988 to September 2006), the Cochrane Central Register of Controlled Trials (CENTRAL_-The Cochrane Library, Issue 3, 2006). Abstracts and proceedings of relevant scientific meetings were hand-searched. The bibliographies of all eligible articles were also examined for relevant stud- ies. Searches used a combination of text words and $\mathrm{MeSH}$ terms. There were no language restrictions.

\section{Selection of Trials}

Titles and abstracts of articles revealed by the search were assessed independently by two authors (AEE, DC). Each potentially relevant study located in the search was obtained in full text and assessed for inclusion independently by the two authors. Doubts were resolved by discussion between all the authors and reexamination of the paper when necessary.

Assessment of trial quality also considered the following features: randomization and allocation concealment, blinding of those providing and receiving the intervention and blinding of the outcome assessor to treatment allocation, baseline clinical characteristics, concomitant treatments, type of outcome measures, losses to follow-up and dropouts, and whether an intention-to-treat analysis was performed.

The studies were classified according to BoNT serotype (A or B) and to specific BoNT/A brands which are dosed using nonequivalent brand units. ${ }^{12}$

\section{Statistical Analysis}

We performed descriptive statistics for trial and study population characteristics across all eligible trials and an intention-to-treat analysis of the data. Missing values for dichotomous outcome measures were assumed to indicate a poor outcome. Missing means and standard deviations were calculated whenever possible. $^{13}$

Dichotomous outcomes were analyzed calculating odds ratios (OR) for each trial with the uncertainty in each results being expressed by their confidence interval (CI). Continuous outcomes were analyzed calculating the Weighted Mean Difference (WMD) or the standardized mean difference (SMD) with 95\% CI. The OR, the WMD, or the SMD from the individual trials were combined through meta-analysis where possible (absence of clinical or statistical heterogeneity) using a fixed effect model unless there was significant statistical heterogeneity, in which case a random effect model was used. Heterogeneity between trials was assessed using the $\mathrm{I}^{2}$ statistic. ${ }^{14}$ Heterogeneity was not judged exclusively on a statistical basis; evidence of clinical heterogeneity among trials (heterogeneity of study populations, interventions, settings, and outcomes between trials) prevented pooling the results. The Review Manager software (version 5) developed by the Cochrane Collaboration was used for data organizing and analysis. 


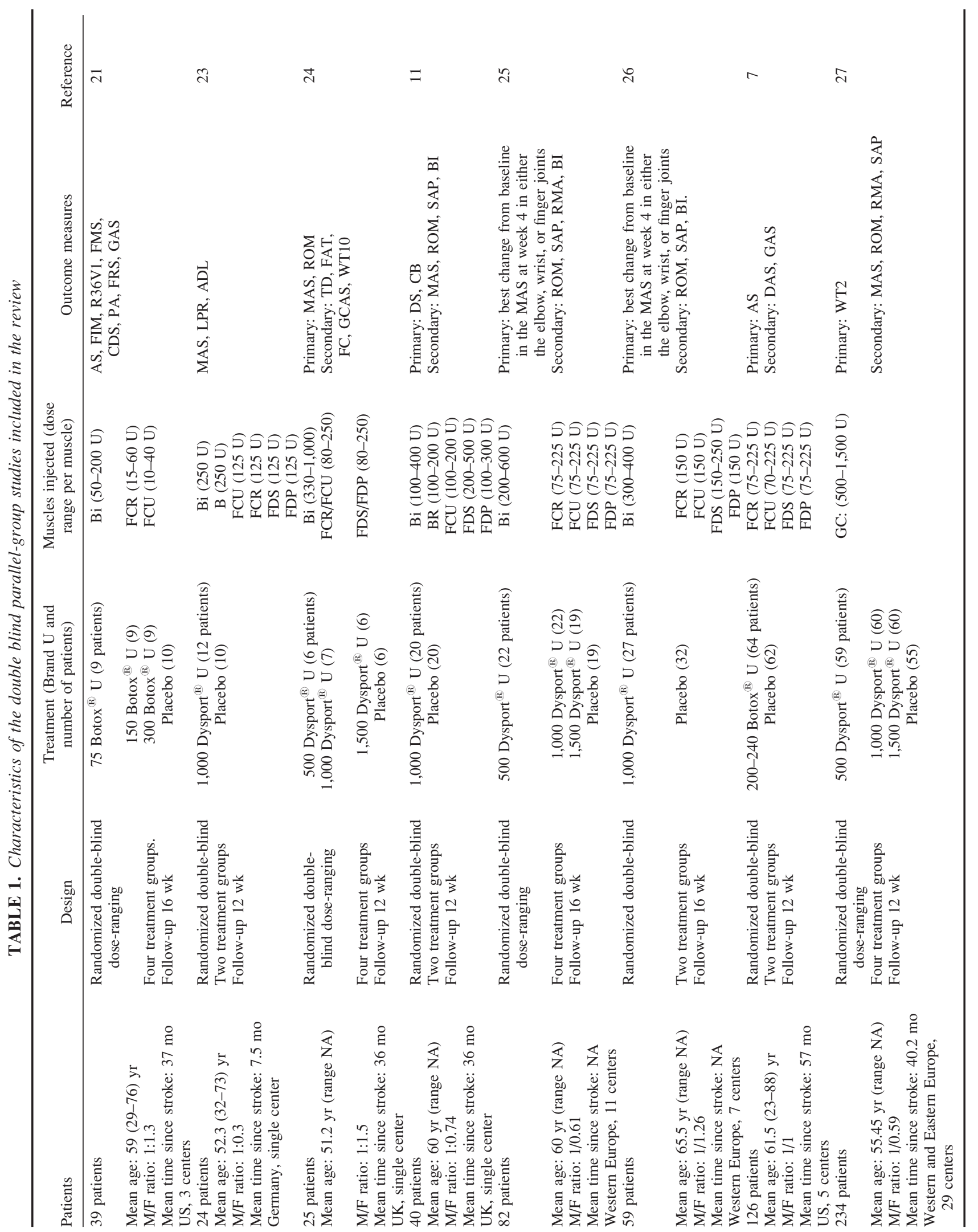




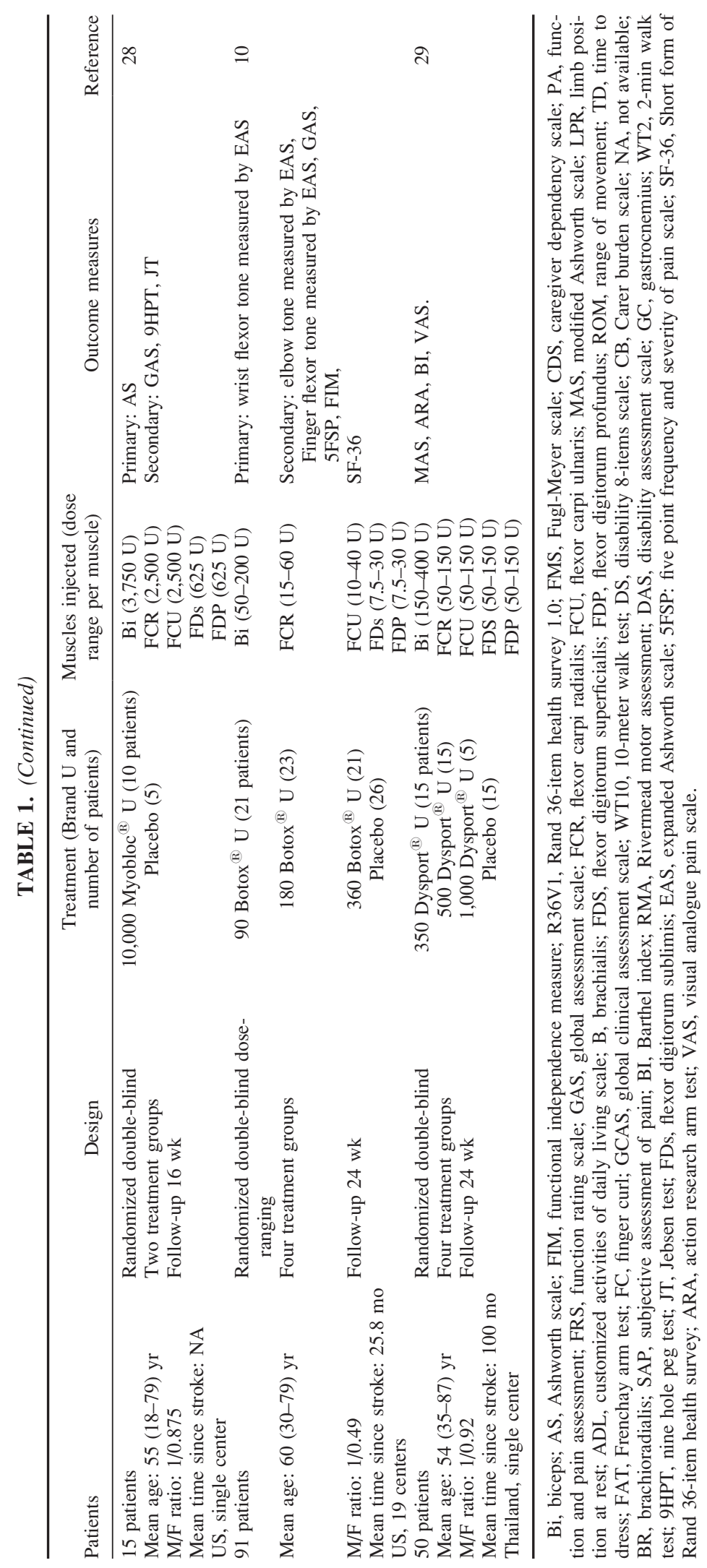


TABLE 2. Quality of trials included in the review

\begin{tabular}{|c|c|c|c|c|c|}
\hline $\begin{array}{l}\text { Allocation } \\
\text { concealment }\end{array}$ & $\begin{array}{l}\text { Double-blinded assessment } \\
\text { of primary outcome }\end{array}$ & $\begin{array}{c}\text { Number }(\%) \text { of patients who were } \\
\text { withdrawn or dropped out }\end{array}$ & $\begin{array}{l}\text { Intention-to-treat } \\
\text { analysis performed }\end{array}$ & $\begin{array}{l}\text { Length of } \\
\text { follow-up (wk) }\end{array}$ & Reference \\
\hline Unclear & Unclear & $2(5)$ & No & 16 & 21 \\
\hline Yes & Yes & $2(5)$ & No & 12 & 11 \\
\hline Unclear & Yes & $1(1)$ & No & 16 & 25 \\
\hline Unclear & Yes & 0 & Yes & 12 & 24 \\
\hline Yes & Yes & 0 & Yes & 16 & 26 \\
\hline Unclear & Yes & $4(3)$ & No & 12 & 7 \\
\hline Unclear & Unclear & $6(2.5)$ & No & 12 & 27 \\
\hline Unclear & Yes & 0 & Yes & 16 & 28 \\
\hline Unclear & Unclear & $14(15)$ & No & 24 & 10 \\
\hline Unclear & Unclear & 0 & Yes & 24 & 29 \\
\hline
\end{tabular}

\section{FINDINGS}

\section{Description of Studies}

We identified 63 references of which 18 were identified as potentially eligible for inclusion in the review. Five studies were excluded because participants were treated with phenol block ${ }^{15,16}$ or casts, ${ }^{17}$ because not all patients had post-stroke spasticity, ${ }^{18}$ or because the data were incomplete. ${ }^{19}$ Two trials were reported both as full length publication and as abstract. ${ }^{10,20-22}$ Thence, the review assessed eleven randomized, placebo-controlled, double-blind trials (Table 1) involving a total of 782 patients.

The methodological quality of the studies is summarized in Table 2. Concealment of treatment allocation was adequate in two trials ${ }^{11,26}$ and unclear in the other nine. . $10,21,23-25,27-29$ Blinding of patients and of the outcome assessor was poorly reported in four studies. ${ }^{10,21,27,29}$ The Ashworth score was used as a primary outcome measure in all trials, but some trials used the scale as a continuous measure, 7,10,11,21,23,24,28 whereas others used it as a categorical measure. ${ }^{25-27,29}$ Overall, $29(3.7 \%)$ patients were excluded by the studies after randomization or loss to follow-up: in one study $^{21}$ no indication of allocation (BoNT vs. placebo) was given for two dropouts; in the other trials there were 15 BoNT-treated dropouts and 12 placebo-treated dropouts. Five trials performed an intention-to-treat analysis. $^{23,24,26,28,29}$

Baseline spasticity was of comparable severity in the BoNT and placebo groups in seven trials, ${ }^{11,21,23,24,26,27,29}$ whereas information on baseline clinical characteristics was considered insufficient in the other four studies. ${ }^{7,10,25,28}$ Considering the potential relevance of concomitant drug treatments, rehabilitation, or devices, this information was not reported in seven trials, ${ }^{7,11,21,24,27-29}$ whereas one study indicated that no patient received concomitant therapy ${ }^{23}$ and three studies reported no between-group differences. $^{10,25,26}$ In two studies, ${ }^{23,29}$ all patients received a concomitant rehabilitation program. Information on clinical side effects and adverse events was reported in all trials, but severe adverse effects were a priori defined in one study only. ${ }^{10}$

\section{Primary Outcome Measures}

Two BoNT/A trials with Dysport ${ }^{\circledR 25,26}$ used the Ashworth score as a categorical measure of primary outcome. In these trials 142 patients were treated in the upper limb.

Results indicated that BoNT/A is efficacious 4 weeks after treatment with 500 Dysport $\mathrm{U}$ or 1,000 Dysport U, whereas there was no significant improvement in Ashworth scores after treatment with 1,500 U (Fig. 1). In another study, ${ }^{29}$ the number of patients with at least two-point reduction in Ashworth score indicated that BoNT/A treatment in the upper limb is efficacious 8 weeks after treatment with doses of 350 (OR: 0.02, 95\% CI: $0.0-0.34, P=0.008$ ), 500 (OR: 0.0, 95\% CI: $0.0-0.06, P<0.0001)$ or 1000 Dysport U (OR: 0.0, 95\% CI: $0.0-0.17, P=0.005$ ). Comparable results were obtained when the analysis was repeated using a one-point score reduction.

Only one study analyzed the effect of BoNT injections in the lower limb. In this dose-ranging study, BoNT was injected in the gastrocnemius muscle at the dose of $500,1,000$, or 1,500 Dysport U. ${ }^{27}$ No significant reduction of spasticity occurred 4,8 , or 12 weeks after treatment, as measured by the number of patients who had at least a two-point reduction of the Ashworth score.

Three BoNT/A studies with Botox ${ }^{\circledR}$, $7,10,21$ involving 184 patients, provided data on the efficacy of BoNT treatment on different upper limb joints. Three to six weeks after treatment, 62 of these patients were assessed for elbow spasticity, 184 for wrist spasticity, 


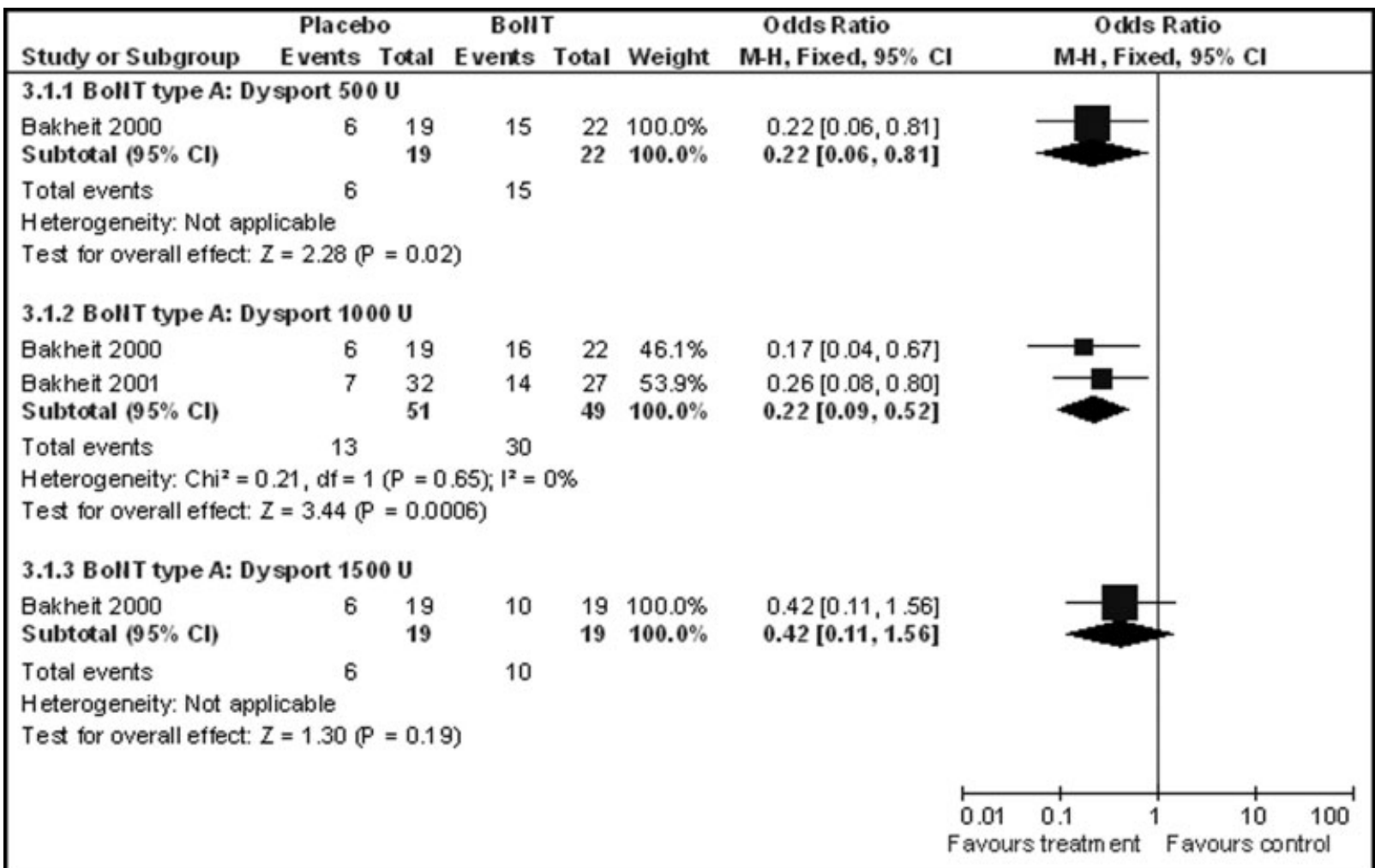

FIG. 1. Numbers of patients with a reduction of Ashworth scores of at least two points in the BoNT/A and placebo groups, 4 weeks after treatment.

and 165 for finger flexor spasticity. The overall effect was significantly in favor of BoNT/A compared with placebo, without evidence of heterogeneity among trials (Fig. 2A). Weighted mean differences of Ashworth scores were $-0.95(P<0.001)$ for elbow, $-1.35(P<$ $0.0001)$ for wrist, and $-1.07(P<0.0001)$ for finger flexor in favor of BoNT. Nine to 12 weeks after treatment, 62 patients were assessed for elbow spasticity, 184 for wrist spasticity, and 122 for finger flexor spasticity. The overall effect was significantly in favor of BoNT/A, with weighted mean differences of $-0.80(P$ $=0.003)$ for elbow spasticity, $-0.83(P<0.001)$ for wrist spasticity, and $-0.76(P<0.001)$ for finger flexor spasticity (Fig. 2B). One trial evaluated BoNT/B in 15 patients and did not find significant effects on upper limb spasticity at 3- to 6-weeks follow-up visits (mean differences of -0.81 for elbow, 95\% CI: -1.94 to $0.32, P=0.16 ;-1.43$ for wrist $95 \% \mathrm{CI}$ : -2.95 to $0.09, P=0.07$; and -1.12 for finger flexor $95 \% \mathrm{CI}$ : -2.47 to $0.23, P=0.1$ ) or at 9 - to 12 -weeks after treatment (mean differences of 0.69 for elbow, 95\% CI: -0.45 to $1.83, P=0.24 ; 0.42$ for wrist, $95 \% \mathrm{CI}$ : -1.29 to $2.13, P=0.63$; and -1.26 for finger flexor, $95 \%$ CI: -3.18 to $0.66, P=0.2) .^{28}$
Three studies with Dysport were not included in the meta-analysis of primary outcomes because standard deviations were not indicated. One of them ${ }^{23}$ analyzed the efficacy of BoNT/A alone or combined with electrical stimulation: it was found that BoNT alone did not reduce Ashworth scores 2, 6, or 12 weeks after a total injection of $1,000 \mathrm{U}$ in elbow, wrist, and finger flexors. The other trial ${ }^{11}$ reported improvement in finger flexor spasticity 2, 6, or 12 weeks after a total injection of 1,000 Dysport $\mathrm{U}$; elbow spasticity was reduced only at 2 weeks after treatment, but not at 6 or 12 weeks. A dose-ranging study $^{24}$ reported no improvement in Ashworth scores at the highest doses employed (1,500 and 1,000 Dysport U), whereas a significant reduction of wrist spasticity was found with the lowest dose (500 Dysport U).

\section{Secondary Outcome Measures}

Two BoNT/A studies with Dysport ${ }^{25,26}$ reported cumulative Ashworth score changes by analyzing the area under the curve over 16 weeks starting from the time of treatment. Results indicated a significant effect in favor of BoNT/A for wrist $(P<0.001)$ and 


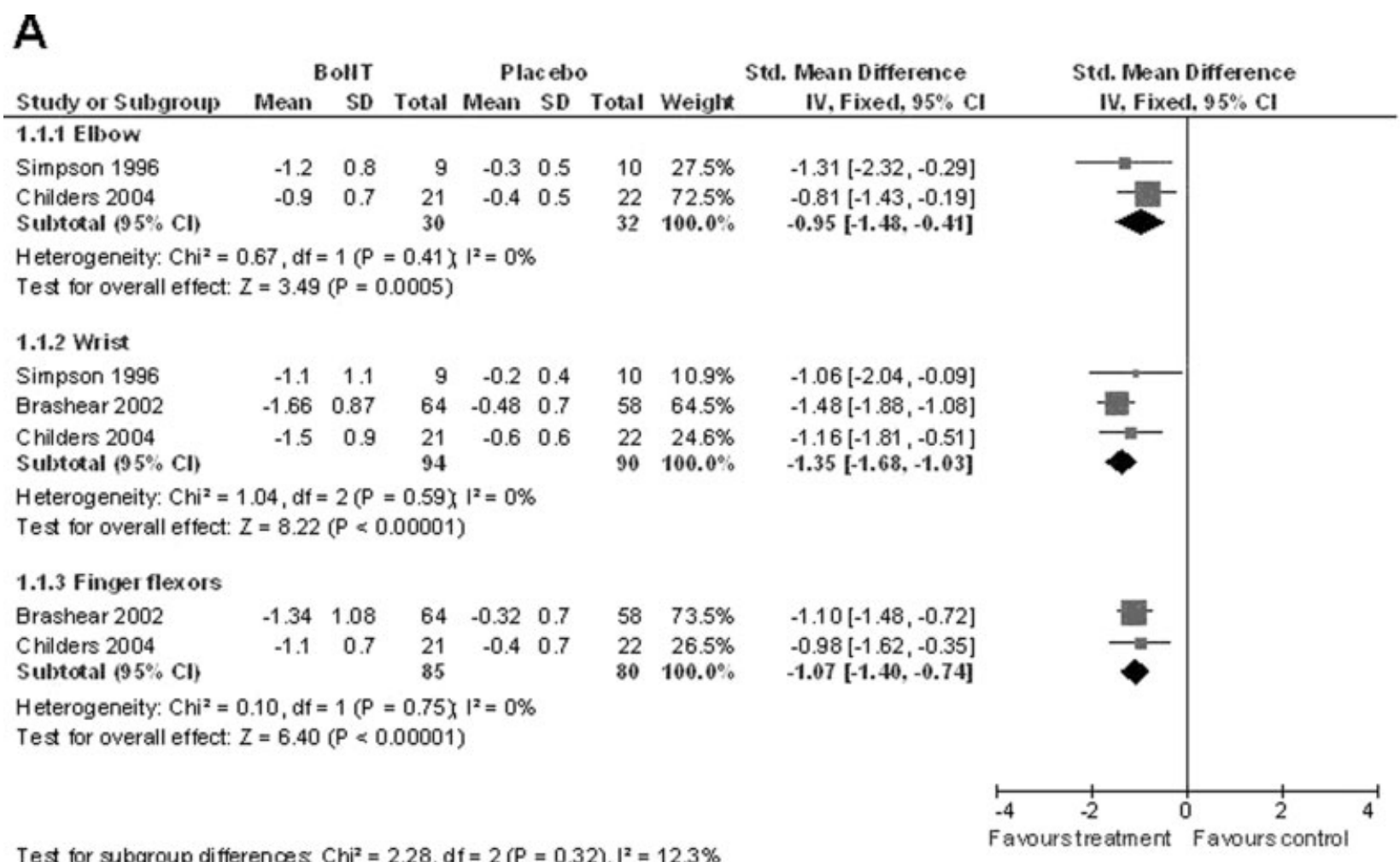

B

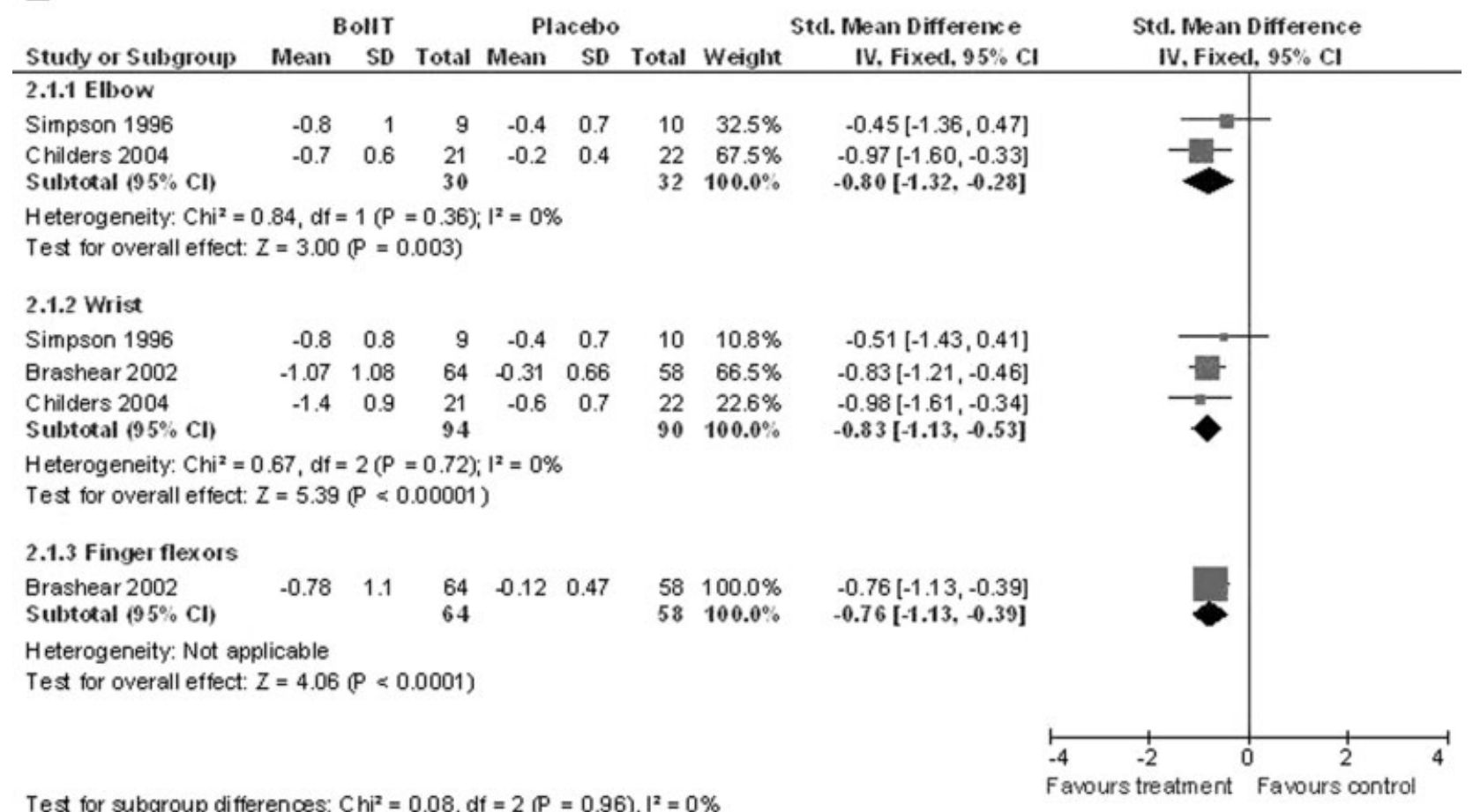

FIG. 2. Mean changes in Ashworth scores for elbow, wrist, and finger flexor spasticity in BoNT/A and placebo-treated patients at 3-6 weeks (A), and 9 to 12 weeks (B) follow-up visits. For dose-ranging studies the highest BoNT/A dose was included in the analysis. 


\begin{tabular}{|c|c|c|c|c|c|c|c|c|c|c|}
\hline \multirow[b]{2}{*}{ Study or Subgroup } & \multicolumn{3}{|c|}{ BoNT } & \multicolumn{3}{|c|}{ Placebo } & \multirow[b]{2}{*}{ Weight } & \multirow{2}{*}{$\begin{array}{l}\text { Mean Difference } \\
\text { T. Random. } 95 \%\end{array}$} & \multirow{2}{*}{\multicolumn{2}{|c|}{$\begin{array}{l}\text { Mean Difference } \\
\text { IV, Random, } 95 \% \mathrm{Cl}\end{array}$}} \\
\hline & Mean & SD & Total & Mean & SD & Total & & & & \\
\hline \multicolumn{11}{|l|}{ 4.1.1 Elbow } \\
\hline Bakheit 2000 & -15 & 13.13 & 22 & -3.2 & 13.86 & 20 & $38.7 \%$ & $-11.80[-19.99,-3.61]$ & & \\
\hline $\begin{array}{l}\text { Bakheit } 2001 \\
\text { Subtotal }(95 \% \mathrm{Cl})\end{array}$ & -10.4 & 11.8 & $\begin{array}{l}27 \\
49\end{array}$ & -8.6 & 7.6 & $\begin{array}{l}32 \\
52\end{array}$ & $\begin{array}{r}61.3 \% \\
100.0 \%\end{array}$ & $\begin{array}{r}-1.80[-6.97,3.37] \\
-6.28[-16.02,3.47]\end{array}$ & & \\
\hline \multicolumn{11}{|c|}{$\begin{array}{l}\text { Heterogeneity: } \operatorname{Tau}^{2}=37.80 ; \mathrm{Chi}^{2}=4.10, \mathrm{df}=1(P=0.04) ; \mathrm{I}^{2}=76 \% \\
\text { Test for overall effect: } Z=1.26(P=0.21)\end{array}$} \\
\hline \multicolumn{11}{|l|}{ 4.1.2 Wrist } \\
\hline Bakheit 2000 & -20.7 & 15.47 & 22 & -6.3 & 16.1 & 20 & $36.5 \%$ & $-14.40[-23.97,-4.83]$ & & \\
\hline $\begin{array}{l}\text { Bakheit } 2001 \\
\text { Subtotal }(95 \% \mathrm{Cl})\end{array}$ & -19.8 & 12.9 & $\begin{array}{l}27 \\
49\end{array}$ & -9.1 & 9.5 & $\begin{array}{l}32 \\
52\end{array}$ & $\begin{array}{r}63.5 \% \\
100.0 \%\end{array}$ & $\begin{array}{l}-10.70[-16.57,-4.83] \\
\mathbf{- 1 1 . 7 1}[-16.72,-6.71]\end{array}$ & & \\
\hline \multicolumn{11}{|c|}{$\begin{array}{l}\text { Heterogeneity: } \text { Tau }^{2}=0.00 ; \mathrm{Chi}^{2}=0.42, \mathrm{df}=1(\mathrm{P}=0.52) ; \mathrm{I}^{2}=0 \% \\
\text { Test for overall effect: } Z=4.59(P<0.00001)\end{array}$} \\
\hline \multicolumn{11}{|l|}{ 4.1.3 Finger flexors } \\
\hline Bakheit 2000 & -16.3 & 15.47 & 22 & -6.3 & 16.1 & 20 & $40.6 \%$ & $-10.00[-19.57,-0.43]$ & & \\
\hline $\begin{array}{l}\text { Bakheit } 2001 \\
\text { Subtotal (95\% Cl) }\end{array}$ & -16.5 & 15 & $\begin{array}{l}27 \\
49\end{array}$ & -9.9 & 11.9 & $\begin{array}{l}32 \\
52\end{array}$ & $\begin{array}{r}59.4 \% \\
100.0 \%\end{array}$ & $\begin{array}{r}-6.60[-13.60,0.40] \\
-7.79[-13.44,-2.14]\end{array}$ & & \\
\hline \multicolumn{11}{|c|}{$\begin{array}{l}\text { Heterogeneity: } \text { Tau }^{2}=0.00 ; \mathrm{Ch}^{2}=0.32, \mathrm{df}=1(P=0.57) ; \mathrm{I}^{2}=0 \% \\
\text { Test for overall effect: } Z=2.70(P=0.007)\end{array}$} \\
\hline & & & & & & & & & $\begin{array}{cc}-20 & -10 \\
\text { Favours treatment }\end{array}$ & 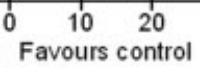 \\
\hline
\end{tabular}

FIG. 3. Area under the curve of Ashworth scores from baseline to 16 weeks in BoNT/A (1000 Dysport U) and placebo treated groups.

finger flexor spasticity $(P=0.007)$, but not for elbow (Fig. 3).

Clinician's judgment concerning the effect of treatment, as measured by the global assessment scale, was in favor of BoNT/A treatment in three trials, ${ }^{7,10,21}$ but not in favor of BoNT/B ${ }^{28}$ (Fig. 4).

Measures of disability were available for nine BoNT/A studies (three using Botox, six using Dys- port), but an overall quantitative analysis could not be performed, because different assessment instruments and scoring systems were used. Two studies found a significant improvement in disability after BoNT/A treatment. $^{7,29}$ One reported that the number of patients with reduced disability, as measured with the Disability Assessment Scale, increased during BoNT/A treatment compared with placebo. ${ }^{7}$ The second reported an

\begin{tabular}{|c|c|c|c|c|c|c|c|c|c|c|}
\hline \multirow[b]{2}{*}{ Study or Subgroup } & \multicolumn{3}{|c|}{ BoNT } & \multicolumn{3}{|c|}{ Placebo } & \multicolumn{2}{|r|}{ Mean Difference } & \multirow{2}{*}{\multicolumn{2}{|c|}{$\begin{array}{l}\text { Mean Difference } \\
\text { IV, Fixed, } 95 \% \mathrm{CI}\end{array}$}} \\
\hline & Mean & SD & Total & Mean & SD & Total & Weight & IV, Fixed, $95 \% \mathrm{Cl}$ & & \\
\hline \multicolumn{11}{|l|}{ 5.1.1 BoNT type A } \\
\hline Simpson 1996 & 1.4 & 0.7 & 9 & 0.2 & 0.4 & 10 & $20.9 \%$ & $1.20[0.68,1.72]$ & & * \\
\hline Brashear 2002 & 1.77 & 0.88 & 64 & 0.57 & 0.86 & 62 & $61.2 \%$ & $1.20[0.90,1.50]$ & & $\mathbf{\square}$ \\
\hline Childers 2004 & 1.7 & 1.1 & 21 & 0.7 & 0.8 & 26 & $17.9 \%$ & $1.00[0.44,1.56]$ & & 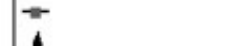 \\
\hline Subtotal $(95 \% \mathrm{Cl})$ & & & 94 & & & 98 & $100.0 \%$ & $1.16[0.93,1.40]$ & & 1 \\
\hline \multicolumn{11}{|c|}{$\begin{array}{l}\text { Heterogeneity: } \mathrm{Chi}^{2}=0.40, \mathrm{df}=2(\mathrm{P}=0.82) ; \mathrm{P}^{2}=0 \% \\
\text { Test for overall effect: } Z=9.60(P<0.00001)\end{array}$} \\
\hline \multicolumn{11}{|l|}{ 5.1.2 BoNT type B } \\
\hline $\begin{array}{l}\text { Brashear } 2004 \\
\text { Subtotal }(95 \% \mathrm{Cl})\end{array}$ & 2.5 & 1.4 & $\begin{array}{l}10 \\
10\end{array}$ & 0.75 & 1.9 & $\begin{array}{l}5 \\
5\end{array}$ & $\begin{array}{l}100.0 \% \\
100.0 \%\end{array}$ & $\begin{array}{l}1.75[-0.13,3.63] \\
1.75[-0.13,3.63]\end{array}$ & & \\
\hline \multicolumn{11}{|c|}{$\begin{array}{l}\text { Heterogeneity: Not applicable } \\
\text { Test for overall effect: } Z=1.83(P=0.07)\end{array}$} \\
\hline & & & & & & & & & -10 & 10 \\
\hline \multicolumn{11}{|c|}{ Test for subgroup cifferences: $\mathrm{Chi}^{2}=0.37, \mathrm{df}=1(\mathrm{P}=0.54), \mathrm{I}^{2}=0 \%$} \\
\hline
\end{tabular}

FIG. 4. Mean changes in global assessment scale for BoNT and placebo treated patients at 4 to 6 weeks follow-up visit. For dose-ranging studies the highest BoNT/A dose was included in the analysis. 
TABLE 3. Adverse events reported in trials included in the review

\begin{tabular}{|c|c|c|}
\hline $\begin{array}{l}\text { Adverse events in BoNT group } \\
\text { (number of patients) }\end{array}$ & Adverse events in placebo group (number of patients) & Reference \\
\hline $\begin{array}{l}\text { Hypothyroidism (1), visceral lymphoma (1), pain due } \\
\text { to spasticity (1) }\end{array}$ & None & 21 \\
\hline None & None & 23 \\
\hline Self limiting arm pain (2), worsening of muscle spasm (1) & $\begin{array}{l}\text { Herpes labialis (1), transient ischaemic attacks (1), } \\
\text { exacerbation of cardiac failure (1) }\end{array}$ & 11 \\
\hline $\begin{array}{l}\text { Epileptic seizures (5), accidental injury (5), urinary and respiratory } \\
\text { tract infections (6) }\end{array}$ & & 25 \\
\hline Hip pain (1), flu-like symptoms (1) & None & 24 \\
\hline Accidental injury (3), urinary and respiratory tract infections (3) & $\begin{array}{l}\text { Accidental injury (3), urinary and respiratory tract } \\
\text { infections (3) }\end{array}$ & 26 \\
\hline $\begin{array}{l}\text { Pain (4), arm pain (2), headache (2), dizziness (1), } \\
\text { incoordination (8), } \\
\text { infection (6), ecchymosis (4), hypoesthesia (4) }\end{array}$ & $\begin{array}{l}\text { Pain (5), arm pain (4), headache (4), dizziness (4), muscular } \\
\text { weakness (4), incoordination (3), infection (3), } \\
\text { ecchymosis (2), hypoesthesia (2) }\end{array}$ & 7 \\
\hline $\begin{array}{l}\text { Pain (2), astenia (1), somnolence (2), abnormal gait (1), } \\
\text { pharyngitis (1), dysphagia (1), headache (1), dizziness (1) }\end{array}$ & $\begin{array}{l}\text { Pain (1), edema (1), parestesia (1), hypertonia (1), } \\
\text { pancreatitis (1) }\end{array}$ & 27 \\
\hline $\begin{array}{l}\text { Decreased lung function, respiratory infection, peripheral edema, } \\
\text { arthralgia, arm pain, hypertension, depression, abdominal pain }\end{array}$ & & 10 \\
\hline Weakness (5), epileptic seizures (4) & $\begin{array}{l}\text { Epileptic seizures (2), accidental injury (1), urinary tract } \\
\text { infection (1) }\end{array}$ & 29 \\
\hline
\end{tabular}

improvement in the Action Research Arm test and the Barthel index following treatment with 500 Dysport U, but a worsening following 1,000 U. ${ }^{29}$ Other studies did not find improvement in disability, as assessed by the functional independence measure, ${ }^{10,21}$ the Barthel index, ${ }^{25,26}$ dressing time and the Frenchay arm test. ${ }^{24}$ In one of these studies, there was a significant improvement in the ability to clean the palm of the affected hand, but this effect occurred only in patients treated with BoNT/A and electrical stimulation. ${ }^{23}$ In three studies global motor function was unchanged, as assessed by the Fugl-Meyer scale ${ }^{21}$ and the Rivermead motor assessment. ${ }^{25,27}$ Disability was not reduced in BoNT/B treated patients compared with placebo, as measured by the Jebsen test or nine-hole peg test. ${ }^{28}$

Information on the frequency and severity of pain was available for eight studies, but these used different methods to assess and score pain; therefore, a metaanalysis could not be performed. Two trials reported a significant pain decrease in patients receiving BoNT/A, that was more evident at doses above 500 Dysport $\mathrm{U}^{27,29}$ The other studies found no reduction in pain, either using BoNT/A (Dysport or Botox) ${ }^{10,11,21,25,26}$ or BoNT/B. ${ }^{28}$

Health-related quality of life was assessed by validated scales in two trials. ${ }^{10,21}$ There was a nonsignificant improvement in the Rand 36-item health survey, ${ }^{21}$ and a significant improvement in the SF-36 in patients who received the lowest BoNT/A dose (90 Botox U). ${ }^{10}$

BoNT/A was well tolerated. No study reported a higher frequency of adverse events in BoNT/A-treated than placebo groups. One study reported excessive weakness in patients treated at the highest BoNT/A dose (1,500 Dysport U). ${ }^{29}$ Only one trial provided information on the incidence of severe adverse effects ${ }^{10}$ : these occurred in 12 of $65(18.4 \%)$ BoNT/A-treated patients and 3 of $26(11.5 \%)$ controls (difference was not significant). None of the serious adverse event was considered treatment-related by the study investigators. In one BoNT/B trial, dry mouth was more common in the treated group than in controls. ${ }^{28}$ A summary of the adverse events is reported in Table 3.

\section{DISCUSSION}

This systematic review provides evidence that a single BoNT/A treatment reduces hypertonia because of post-stroke spasticity, measured by the clinician with the Ashworth score in elbow, wrist, and finger flexors 1 month after treatment. Nine to 12 weeks after treatment, the effect of BoNT/A is maintained in distal upper limb joints, but is less evident at the elbow, where the results of two studies conflict. ${ }^{10,21}$ This is in keeping with the observation that measurements of the area under the curve (until 16 weeks after treatment) did not show significant effects on elbow spasticity. The inconsistent results on elbow may be due to the small sample size of patients evaluated at this joint, or to insufficient doses injected into the larger proximal muscles, considering that the clinical effects of BoNT/ $\mathrm{A}$ are dose-dependent. ${ }^{30}$ Previous reviews on the efficacy of BoNT considered the upper limb as a whole $\mathrm{e}^{31-33}$ 
and could not identify distal-to-proximal variations in outcome. The doses used for the smaller muscles varied consistently in the studies included in this review and it was not possible to establish a minimal efficacious dose. The dose range in finger flexors varied from 7.5 to 225 Botox U, from 100 to 500 Dysport $\mathrm{U}$, or from 625 to 2,500 Myobloc ${ }^{\circledR} \mathrm{U}$.

In this review, we evaluated the outcome in upper limb joints and found that clinical improvement is more consistent for distal joints. A similar evaluation was not performed for the lower limb, as only one study on the lower limb spasticity could be included based on our strict criteria $^{27}$; the other available trials were excluded because the patients were also treated with casts, ${ }^{17}$ or they did not all have post-stroke spasticity, ${ }^{18}$ or the data were incomplete. ${ }^{19}$ The results of the lower limb spasticity study included showed no significant improvement in walking or spasticity ${ }^{27}$ following injection in the gastrocnemius muscle. This evidence is very limited, because several other muscles (including the tibialis anterior and posterior, flexor and extensor digitorum or the peroneal muscles) are involved in post-stroke lower limb spasticity. Overall, the available information indicates the need for further good quality studies assessing the efficacy of BoNT on lower limb spasticity.

Heterogeneity of outcome measures in the nine randomized controlled trials and some relevant weaknesses made it difficult to pool the data on patients with stabilized post-stroke spasticity. A common ground to the studies reviewed was provided by the use of Ashworth scale as the primary outcome measure. Although usage of this scale has been questioned based on the fact that it evaluates resistance to passive movements rather than spasticity, ${ }^{34}$ it remains the most widely-used outcome measure in clinical trials, and has fair inter-rater reliability. ${ }^{6}$ The commonest flaws of the studies analyzed were unclear randomization methods, uncertain concealment of allocation, and doubtful blinding of primary outcome measurement, which is particularly relevant in this case because the Ashworth score is a soft outcome measure. Baseline information was considered insufficient in four studies, ${ }^{7,10,25,28}$ and six studies did not perform intention-to-treat analyses: these potentially severe limitations were mitigated by the observation that dropout rates after randomization were low (between $1 \%$ and $15 \%$ ).

Muscle selection is a key feature for the efficacy of BoNT treatment and the injection techniques are a further source of heterogeneity. Four trials did not mention how the muscles were targeted, ${ }^{11,24,28}$ three used surface landmarks, ${ }^{25-27}$ three used needle EMG guid- ance, ${ }^{10,21,29}$ and one study used both EMG targeting and electrical stimulation. ${ }^{23}$ There is evidence from dystonia that EMG targeting increases accuracy and improves outcome ${ }^{35}$; however, when high doses are injected into sufficiently large muscles, as in the spasticity studies reviewed here, toxin diffusion compensates for this limitation.

Most patients had ischemic strokes, and about 25\% had hemorrhagic strokes. This finding is consistent with the prevalence of stroke types ${ }^{36}$ and indicates that the stroke case mix of the patients reviewed is realistic. The large number of patients assessed, their provenance from various countries, and realistic stroke case mix all suggest that the findings of this systematic review have good external validity. Earlier, more limited, analyses provided results, which are encompassed by the present review, ${ }^{31}$ which also indicates that available data on BoNT/B are insufficient to assess its effect on spasticity and that further controlled trials using BoNT/B are necessary.

The reported reductions in muscle tone were measured on average 1 month and 3 months after treatment, similarly with the duration of BoNT effect seen in dystonia. ${ }^{37,38}$ Although the duration of BoNT action in patients with spasticity was not specifically addressed by the studies reviewed, they suggested that some efficacy persists 6 weeks after injection and up to 9 to 12 weeks. ${ }^{7,10,11,21}$ In dystonia patients, BoNT injections are usually repeated at regular intervals. It is likely that repeated treatments are also efficacious in patients with spasticity, but there is limited available evidence in support. Only one open trial addressed this issue, reporting that a higher number of patients in the BoNT group than in the placebo group improved after a second treatment session performed 3 months after the first one. ${ }^{10}$ Another open label trial mentioned that improvement in spasticity was maintained for three consecutive BoNT/A treatments at different intervals of 3,4 , or 5 months, as clinically indicated. ${ }^{39}$ Adequate management of patients with post-stroke spasticity requires knowledge of long-term outcomes following repeated BoNT treatments-an aspect that remains to be addressed by specific studies.

No study reported more serious adverse events in the treatment than placebo arms, indicating that BoNT/ A can be considered a safe treatment in adults. A recent FDA communication was issued regarding cases of botulism-like symptoms with the use of BoNT/A or BoNT/B prevalently in children treated for limb spasticity. ${ }^{40}$ Excessive weakness occurred in the reviewed papers after injections of high Dysport doses (1,500 U) in the upper limb, ${ }^{29}$ consistent with similar reports on 
patients with multiple sclerosis ${ }^{41}$ and cerebral palsy. ${ }^{42}$ Available data on BoNT/A usage in patients with dystonia and other movement disorders also indicate a similar safety profile. $^{43}$ A pooled analysis concluded that nausea was the most frequent minor adverse event in post-stroke patients treated with BoNT/A, affecting only $2.2 \%$ of cases. $^{44}$ BoNT/B may have more side effects than BoNT/A, particularly on autonomic function. This is suggested not only by the study included in the present review, ${ }^{28}$ but also by trials with BoNT/B for other indications. ${ }^{45}$

Six studies reported inconsistent and conflicting results on pain reduction in the upper limb following BoNT treatment, ${ }^{10,11,21,25,26,28}$ whereas one controlled study showed significant pain reduction in the lower limb. ${ }^{27}$ These inconsistencies in secondary outcome measures are likely explained by the heterogeneity of patients included and by the lack of systematic evaluation of pain or disability as outcome measures.

We reviewed all validated measures of disability, activities of daily living, and quality of life. Most of the reviewed studies did not support an effect of BoNT/A on these outcomes, ${ }^{10,21,25-27}$ whereas two studies reported functional improvement on active function. $^{7,29}$ To resolve this inconsistency, new studies need to be planned in which function is a primary outcome measure. Because spasticity is only one among several clinical signs of post-stroke syndrome, ${ }^{1}$ treatment with BoNT may not be sufficient to produce a demonstrable improvement in motor function, because of the persistence of remaining features not managed by this treatment. A methodological fault of the reviewed studies is that the experimental design did not correspond to usual clinical care, and multidisciplinary management of the patients was not performed. BoNT treatment is only one out of several interventions in the comprehensive management of upper motor neuron syndrome and is commonly associated with physical therapy. ${ }^{46}$ Because post-stroke rehabilitation is efficacious, ${ }^{47}$ future BoNT trials should consider patients under standard rehabilitation programs. Furthermore, the time lag between the acute event and BoNT treatment also needs to be stratified in future trials, as in the studies reviewed here the lag of treatment was quite variable (ranging from 3 months to 8 years after the acute event).

BoNT is increasingly being used in patients with spasticity as an alternative or add-on to other symptomatic treatments. It is safe and superior to placebo in reducing stabilized upper limb spasticity. The quality of functional improvement after BoNT treatment remains a point of uncertainty, which requires to be specifically addressed. Future research should also aim to identify which patients may best benefit from BoNT treatment, either on motor or on functional features, and set criteria for their selection. Patient groups need to be stratified for secondary variables, such as pain or disability. Recently, a guideline on the efficacy of BoNT for the treatment of spasticity was issued, ${ }^{33}$ but currently there are no guidelines for the multidisciplinary and comprehensive management of patients with spasticity. This seems to be an appropriate goal for future efforts.

Acknowledgments: This work was supported in part by the Italian Ministry of Health. We thank the Cochrane Collaboration for permitting usage of the Review Manager software (version 5).

Author Roles: A. E. Elia: research project, execution; statistical analysis, execution; Manuscript, writing of the first draft. G. Filippini: research project, conception; manuscript: review and critique. D. Calandrella: research project, execution. A. Albanese: research project, conception; manuscript, review and critique.

\section{REFERENCES}

1. Mayer NH, Esquenazi A. Muscle overactivity and movement dysfunction in the upper motoneuron syndrome. Phys Med Rehabil Clin N Am 2003; 14:855-883.

2. Lance JW. The control of muscle tone, reflexes, and movement: Robert Wartenberg lecture. Neurology 1980;30:1303-1313.

3. Sheean GL. Botulinum treatment of spasticity: why is it so difficult to show a functional benefit? Curr Opin Neurol 2001;14: $771-776$

4. Esquenazi A. Improvements in healthcare and cost benefits associated with botulinum toxin treatment of spasticity and muscle overactivity. Eur J Neurol 2006;13 (Suppl 4):27-34.

5. Woldag $\mathrm{H}$, Hummelsheim $\mathrm{H}$. Is the reduction of spasticity by botulinum toxin a beneficial for the recovery of motor function of arm and hand in stroke patients? Eur Neurol 2003;50:165171.

6. Platz T, Eickhof C, Nuyens G, Vuadens P. Clinical scales for the assessment of spasticity, associated phenomena, and function: a systematic review of the literature. Disabil Rehabil 2005;27:718.

7. Brashear A, Gordon MF, Elovic E, et al. Intramuscular injection of botulinum toxin for the treatment of wrist and finger spasticity after a stroke. N Engl J Med 2002;347:395-400.

8. Ashworth B. Preliminary trial of carisoprodol in multiple sclerosis. Practitioner 1964;192:540-542.

9. Bohannon RW, Smith MB. Interrater reliability of a modified Ashworth scale of muscle spasticity. Phys Ther 1987;67:206-207.

10. Childers MK, Brashear A, Jozefczyk P, et al. Dose-dependent response to intramuscular botulinum toxin type A for upper-limb spasticity in patients after a stroke. Arch Phys Med Rehabil 2004;85:1063-1069.

11. Bhakta BB, Cozens JA, Chamberlain MA, Bamford JM. Impact of botulinum toxin type A on disability and carer burden due to arm spasticity after stroke: a randomised double blind placebo controlled trial. J Neurol Neurosurg Psychiatry 2000;69:217-221.

12. Wenzel R, Jones D, Borrego JA. Comparing two botulinum toxin type A formulations using manufacturers' product summaries. J Clin Pharm Ther 2007;32:387-402. 
13. Cochrane Handbook for Systematic Reviews of Interventions. 2007. (Internet communication).

14. Higgins J, Thompson S, Deeks J, Altman D. Statistical heterogeneity in systematic reviews of clinical trials: a critical appraisal of guidelines and practice. J Health Serv Res Policy 2002;7:51-61.

15. On AY, Kirazli Y, Kismali B, Aksit R. Mechanisms of action of phenol block and botulinus toxin type A in relieving spasticity: electrophysiologic investigation and follow-up. Am J Phys Med Rehabil 1999;78:344-349.

16. Kirazli Y, On AY, Kismali B, Aksit R. Comparison of phenol block and botulinus toxin type $\mathrm{A}$ in the treatment of spastic foot after stroke: a randomized, double-blind trial. Am J Phys Med Rehabil 1998;77:510-515.

17. Verplancke D, Snape S, Salisbury CF, Jones PW, Ward AB. A randomized controlled trial of botulinum toxin on lower limb spasticity following acute acquired severe brain injury. Clin Rehabil 2005; 19:117-125.

18. Richardson D, Sheean G, Werring D, et al. Evaluating the role of botulinum toxin in the management of focal hypertonia in adults. J Neurol Neurosurg Psychiatry 2000;69:499-506.

19. Burbaud P, Wiart L, Dubos JL, et al. A randomised, double blind, placebo controlled trial of botulinum toxin in the treatment of spastic foot in hemiparetic patients. J Neurol Neurosurg Psychiatry 1996;61:265-269.

20. O'Brien CF, Simpson DM, Alexander DN, Tagliati M, Aswad AS, Gibson J. A randomized, doubleblind, placebo-controlled study to evaluate the use of botulinum toxin type A in the treatment of spasticity. Neurology 1995;45(4 Suppl 4):A329.

21. Simpson DM, Alexander DN, O'Brien CF, et al. Botulinum toxin type $\mathrm{A}$ in the treatment of upper extremity spasticity: a randomized, double-blind, placebo-controlled trial. Neurology 1996;46: 1306-1310.

22. Childers MK, Brashear A, Jozefczyk PB, Reding MJ, Dru RM, Lee $\mathrm{CH}$. A multicenter, double-blind, placebo-controlled dose response trial of botulinum toxin type $A$ (Botox ${ }^{\mathbb{R}}$ ) in upper limb spasticity poststroke. Neurology 1999;52(6 Suppl 2):A295.

23. Hesse S, Reiter F, Konrad M, Jahnke MT. Botulinum toxin type A and short-term electrical stimulation in the treatment of upper limb flexor spasticity after stroke: a randomized, double-blind, placebo-controlled trial. Clin Rehabil 1998;12:381-388.

24. Smith SJ, Ellis E, White S, Moore AP. A double-blind placebocontrolled study of botulinum toxin in upper limb spasticity after stroke or head injury. Clin Rehabil 2000;14:5-13.

25. Bakheit AM, Thilmann AF, Ward AB, et al. A randomized, double-blind, placebo-controlled, dose-ranging study to compare the efficacy and safety of three doses of botulinum toxin type A (Dysport) with placebo in upper limb spasticity after stroke. Stroke 2000;31:2402-2406.

26. Bakheit AM, Pittock S, Moore AP, et al. A randomized, doubleblind, placebo-controlled study of the efficacy and safety of botulinum toxin type A in upper limb spasticity in patients with stroke. Eur J Neurol 2001;8:559-565.

27. Pittock SJ, Moore AP, Hardiman O, et al. A double-blind randomised placebo-controlled evaluation of three doses of botulinum toxin type A (Dysport) in the treatment of spastic equinovarus deformity after stroke. Cerebrovasc Dis 2003;15:289-300.

28. Brashear A, McAfee AL, Kuhn ER, Fyffe J. Botulinum toxin type B in upper-limb poststroke spasticity: a double-blind, placebo-controlled trial. Arch Phys Med Rehabil 2004;85:705-709.

29. Suputtitada A, Suwanwela NC. The lowest effective dose of botulinum A toxin in adult patients with upper limb spasticity. Disabil Rehabil 2005;27:176-184.
30. Albanese A, Bentivoglio AR. Botulinum toxin in movement disorders. In: Jankovic J, Tolosa E, editors. Parkinson's disease and movement disorders, 5th ed. Philadelphia: Lippincott Williams \& Wilkins; 2007. pp 605-619.

31. Cardoso E, Rodrigues B, Lucena R, Oliveira IR, Pedreira G, Melo A. Botulinum toxin type A for the treatment of the upper limb spasticity after stroke: a meta-analysis. Arq Neuropsiquiatr 2005;63:30-33.

32. Sheean G. Botulinum toxin treatment of adult spasticity: a benefit-risk assessment. Drug Saf 2006;29:31-48.

33. Simpson DM, Gracies JM, Graham HK, et al. Assessment: botulinum neurotoxin for the treatment of spasticity (an evidencebased review): report of the Therapeutics and Technology Assessment Subcommittee of the American Academy of Neurology. Neurology 2008;70:1691-1698.

34. Pandyan AD, Johnson GR, Price CI, Curless RH, Barnes MP, Rodgers H. A review of the properties and limitations of the Ashworth and modified Ashworth Scales as measures of spasticity. Clin Rehabil 1999;13:373-383.

35. Cordivari C, Misra VP, Vincent A, Catania S, Bhatia KP, Lees AJ. Secondary nonresponsiveness to botulinum toxin A in cervical dystonia: the role of electromyogram-guided injections, botulinum toxin A antibody assay, and the extensor digitorum brevis test. Mov Disord 2006;21:1737-1741.

36. Sudlow CL, Warlow CP. Comparable studies of the incidence of stroke and its pathological types: results from an international collaboration, International Stroke Incidence Collaboration. Stroke 1997;28:491-499.

37. Jankovic J, Schwartz K. Botulinum toxin injections for cervical dystonia. Neurology 1990;40:277-280.

38. Bentivoglio AR, Albanese A. Botulinum toxin in motor disorders. Curr Opin Neurol 1999;12:447-456.

39. Bakheit AM, Fedorova NV, Skoromets AA, Timerbaeva SL, Bhakta BB, Coxon L. The beneficial antispasticity effect of botulinum toxin type $\mathrm{A}$ is maintained after repeated treatment cycles. J Neurol Neurosurg Psychiatry 2004;75:15581561 .

40. U.S.Food and Drug Administration. Early communication about an ongoing safety review Botox and Botox Cosmetic (botulinum toxin type A) and Myobloc (botulinum toxin type B). 2008 (Internet Communication).

41. Shakespeare DT, Boggild M, Young C. Anti-spasticity agents for multiple sclerosis. Cochrane Database Syst Rev 2003;4: CD001332.

42. Wasiak J, Hoare B, Wallen M. Botulinum toxin A as an adjunct to treatment in the management of the upper limb in children with spastic cerebral palsy. Cochrane Database Syst Rev 2004;4: CD003469.

43. Naumann M, Jankovic J. Safety of botulinum toxin type A: a systematic review and meta-analysis. Curr Med Res Opin 2004; 20:981-990.

44. Turkel CC, Bowen B, Liu J, Brin MF. Pooled analysis of the safety of botulinum toxin type $\mathrm{A}$ in the treatment of poststroke spasticity. Arch Phys Med Rehabil 2006;87:786792.

45. Dressler D, Eleopra R. Clinical use of non-A botulinum toxins: botulinum toxin type B. Neurotox Res 2006;9:121-125.

46. Ward AB. A summary of spasticity management-a treatment algorithm. Eur J Neurol 2002;9 (Suppl. 1):48-52.

47. Outpatient Service Trialists. Therapy-based rehabilitation services for stroke patients at home. Cochrane Database Syst Rev 2003; 1:CD002925. 